\title{
Short-Rib Thoracic Dysplasia 6 with or without Polydactyly
}

National Cancer Institute

\section{Source}

National Cancer Institute. Short-Rib Thoracic Dysplasia 6 with or without Polydactyly. NCI Thesaurus. Code C122654.

A group of rare, autosomal recessive inherited disorders characterized by a constricted thoracic cage, short ribs, and a 'trident' appearance of the acetabular roof. Polydactyly may or may not be present. Other abnormalities include cleft lip and palate and abnormalities of the brain, eye, heart, liver, pancreas, intestine, kidney, and genitalia. 